\title{
Evolución urbana de un sector de la ciudad de Tortosa durante la Antigüedad: intervenciones arqueológicas en la calle de Sant Domènech
}

\author{
Urban development of an area of the city of Tortosa in \\ Antiquity: archaeological excavations in Sant Domènech street
}

\author{
Jordi Diloli Fons \\ Universitat Rovira i Virgili de Tarragona \\ Ramon Ferré Anguix \\ Grup de Recerca Seminari de Protohistòria i Arqueologia de la URV \\ Sergi Navarro Just \\ Arqueólogo \\ Jordi Vilà Llorach \\ Grup de Recerca Seminari de Protohistòria i Arqueologia de la URV
}

\section{RESUMEN}

El estudio del pasado antiguo de Tortosa adolece de un retraso de varias décadas respecto al de otras ciudades con un patrimonio semejante. Para paliar este déficit, hace ya algunos años que el Seminari de Protohistoria i Arqueologia (GRESEPIA) de la Universitat Rovira i Virgili de Tarragona está llevando a cabo un proyecto de investigación, con unos resultados muy interesantes proporcionados, entre otras, por las intervenciones arqueológicas llevadas a cabo en la calle Sant Domènech de Tortosa. En este sector del casco antiguo de la ciudad han aparecido dos sepulturas correspondientes a una extensa área de necrópolis bajo-imperial, varias estructuras alto-imperiales, y finalmente, los restos de una fortificación ibérica. El hallazgo de esta construcción defensiva supone la confirmación de la existencia, largamente hipotetizada, de un importante oppidum prerromano en el cerro de la Zuda, que dominaría el núcleo antiguo de la ciudad.

\section{SUMMARY}

The study of the ancient past of the city of Tortosa suffers from a delay of several decades in comparison with other cities with a similar heritage. In order to mitigate that lack, the Seminari de Protohistòria i Arqueologia (GRESEPIA) de la Universitat Rovira i Virgili, of Tarragona, has been leading a research project that has provided very interesting results, particulary from the archaeological excavations carried out in Sant Domènech street in Tortosa. In this area of the old part of the city, two graves belonging to an extensive late Roman necropolis have been discovered, as well as several early Roman walls and, what is more significant, the remains of an iberian fortification. The discovery of this fortification confirms the long-speculated presence of an important pre-roman oppidum at the top of the Zuda hill, in the middle of the old part of the city.
PALABRAS CLAVES: Dertosa, río Ebro, iberos, época romana, fortificación, necrópolis, Protohistoria.

KEY WORDS: Dertosa, Ebro river, Iberians, Roman epoch, fortification, necropolis, Protohistory.

\section{INTRODUCCIÓN}

Hasta fechas muy recientes, la ocupación prerromana del solar donde hoy se ubica la ciudad de Tortosa no había pasado de mera hipótesis, a pesar de las sugerentes informaciones proporcionadas por los autores clásicos, los indicios numismáticos y las reflexiones de la historiografía moderna, a los que se añade en nuestros días la investigación científica, basada en los distintos trabajos arqueológicos efectuados en la ciudad y su entorno durante los últimos años (Diloli 1996; 1997; Diloli y Ferré 2008b). Gracias a este avance en la investigación que se ha llevado a cabo en la ciudad, se han podido localizar por primera vez restos de estructuras asociadas a niveles arqueológicos plenamente ibéricos, hecho que confirma la existencia de un núcleo prerromano que se intuía y que para muchos estudiosos, siguiendo los datos aportados fundamentalmente por Tito Livio, sería la ciudad de Hibera, la misma que habría dirigido políticamente el territorio ibérico del tramo final del río Ebro.

Para la época romana, el estado de la cuestión sobre la fundación y evolución urbanística de la ciu- 
dad de Dertosa tampoco es satisfactorio, ya que la ciudad nunca ha participado en proyectos específicos de investigación orientados al análisis de su desarrollo urbano, de modo que las intervenciones de tipo arqueológico que se han efectuado en el municipio han sido motivadas sobre todo por las necesidades derivadas de la existencia de una Llei del Patrimoni Cultural Català, con unos objetivos limitados por el propio desarrollo de las obras que las generaban, y no por un afán de conocer y entender la evolución de la ciudad y su transformación en la Tortosa moderna.

Cuanto menos, no pueden pasarse por alto las actuaciones realizadas en Tortosa con anterioridad a la creación del Servei d'Arqueologia de la Generalitat de Catalunya, pues han sido estas intervenciones las que han permitido documentar los restos de un pasado perdido hoy en día, a pesar de que, en algunos casos, buena parte del material recogido no se reunió siguiendo criterios arqueológicos.

A este hecho debemos sumarle la problemática que supone la topografía tortosina, con una capa freática que tiene actualmente un nivel superior al de época romana, factor que determina la dificultad para localizar estructuras y materiales con una cronología anterior a los siglos IV y V d.C. En realidad, son pocas las excavaciones que han alcanzado estratigrafía de cronología romana en los últimos años (Curto et alii 1986; Genera 1993; Barrasetas 1993; Arbeloa 2000) y estas proporcionan datos muy inconexos, todo lo cual resulta en un importante desconocimiento de los aspectos básicos del desarrollo histórico y urbanístico de la ciudad antigua, a pesar de los compendios de los datos conocidos que se han centrado en el tema, con mayor o menor acierto, publicados recientemente (Járrega 2007; Arbeloa 2008; Genera y Járrega 2009) y que no añaden nuevas informaciones, sobre todo en lo concerniente a la época ibérica, remitiéndose a los poco conclusivos estudios previos (Genera y Járrega 2010).

Estas carencias y la voluntad de suplirlas, han sido un incentivo fundamental para la implementación por parte del Seminario de Protohistoria y Arqueología (GRESEPIA) de la Universidad Rovira i Virgili de Tarragona, del proyecto Anàlisi històrica i arqueològica de l'evolució urbana de la ciutat de Tortosa des de la seva fundació fins a l'antiguitat tardana, con la intención de efectuar un paso adelante cualitativo en el conocimiento de la ciudad desde la Protohistoria hasta la conquista musulmana, aumentando e integrando los datos, hasta ahora dispersos, que poseemos sobre los primeros siglos de historia del municipio. Fruto reciente de estos esfuerzos es, entre otros, el análisis científico de las necrópolis bajo imperiales del barranco del Rastre (Navarro 2008; Diloli et alii 2010).
Es así que no pretendemos con este artículo repetir datos o aseveraciones que otros autores han ido avanzando los últimos años, en algunos casos a partir de referencias extraídas de trabajos efectuados por nuestro Grupo de Investigación, y retomar el debate baldío sobre temas urbanísticos, la ubicación del puerto o los límites de la muralla romana de Dertosa. En este aspecto, las intervenciones que los últimos años hemos efectuado en el Barri del Castell (calle Sant Francesc Neri), en la calle Montcada o en la calle de la Mercè, entre otras, pueden aportar información muy importante para clarificar algunos de los aspectos mencionados.

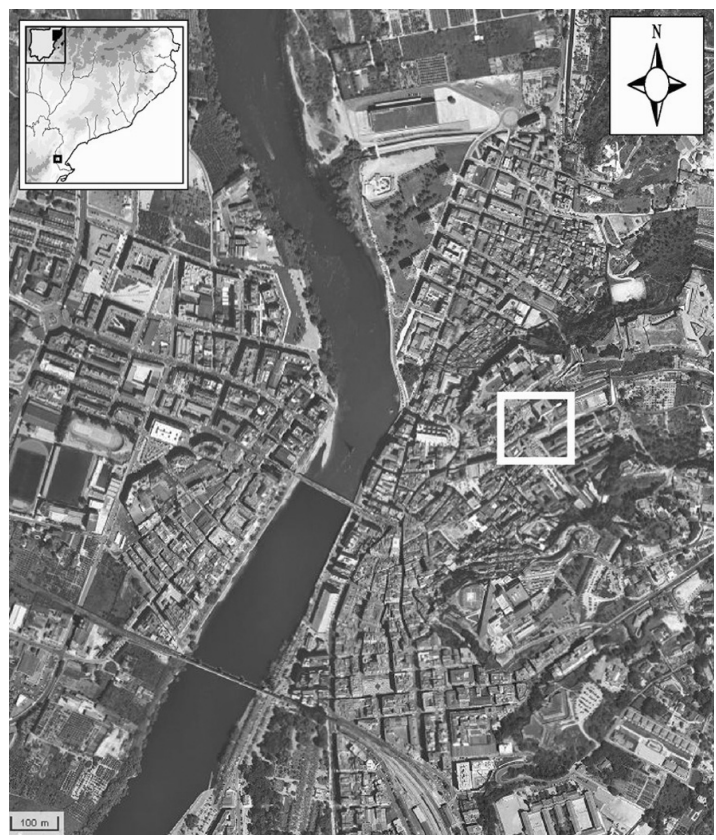

Figura 1. Situación del área Sant Domènech en Tortosa (Baix Ebre, Tarragona).

\section{LAS INTERVENCIONES}

Los trabajos que presentamos en este estudio son el resultado de una intervención efectuada a partir de las obras de mejora del casco antiguo de Tortosa, concretamente en el fondo de la ladera oriental/meridional del tozal de la Zuda, en el llamado "espacio Sant Domènech", que comprende la iglesia renacentista y la calle del mismo nombre. En este lugar se llevaron a cabo una serie de sondeos y una excavación parcial del extremo norte de la calle para conocer la estratigrafía antigua de esta zona de la ciudad.

Como precedente directo de esta actuación hay que citar el seguimiento de la excavación de un antiguo 
trujal efectuado en 1968, llevado a cabo por el entonces director del Museo de Tortosa, Jesús Massip, quien elaboró una secuencia estratigráfica sobre la base de los materiales cerámicos recogidos, entre los que figuraba cerámica andalusí, romana, lo que él denominó como "restos neolíticos de cerámica negra" (Massip 1968), y que seguramente era cerámica de época tardo-antigua, pero también cerámica ibérica, tal como pudimos comprobar recientemente (Diloli y Ferré 2008b).

Los trabajos arqueológicos se llevaron a cabo a lo largo de dos campañas. Una primera en Junio de 2006, en el subsuelo de la iglesia de Sant Domènech y la segunda en el exterior del templo, entre Abril y Julio de 2007. En el interior de la iglesia se practicaron dos sondeos, una cata en un extremo de la iglesia, bajo el coro, y una segunda cata en el centro de la nave; el tercer sondeo se practicó en el exterior del recinto eclesiástico. La segunda fase, ya en 2007, fue la excavación en extensión del tramo final de la calle de Sant Domènech.

\subsection{Excavación en la iglesia de Sant Domènech}

Durante la primera intervención, efectuada como se ha indicado en el interior de la iglesia, se halló en

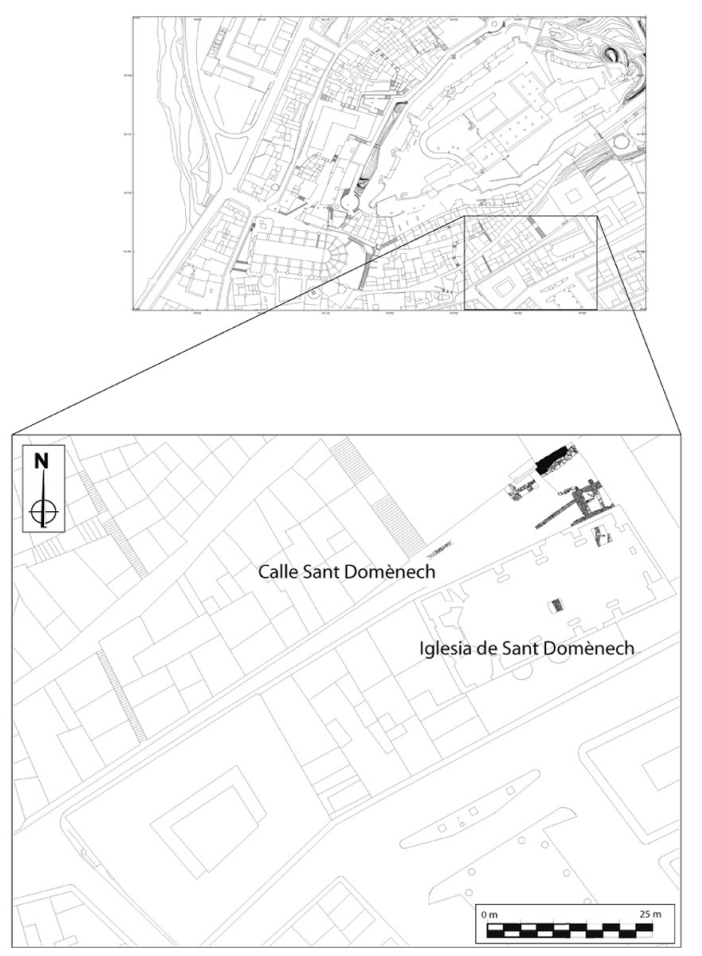

Figura 2. Vista del área de intervención con detalle de los restos exhumados. ambos sondeos bajo el pavimento contemporáneo, una importante potencia estratigráfica de cronología bajo medieval y también andalusí, factor que dificultó el avance de las excavaciones, hasta el punto que una de las dos catas tuvo que ser clausurada por el descubrimiento de un gran muro que ocupaba prácticamente la mitad de la superficie abierta. La excavación de la segunda cata, si bien también dejó al descubierto una estructura mural de cierta entidad, pudo proseguirse hasta alcanzar estratos de cronología romana, con la localización de una inhumación, que fue excavada solo en parte, dado que la mayor parte del cuerpo se perdía fuera de los límites del área de intervención. Aunque no se localizaron clavos de hierro, puede suponerse que se trataría de una inhumación en caja de madera, siguiendo los patrones habituales en esta época en espacios similares. Esta tumba recortaba un estrato de acumulación de sedimentos, rico en material cerámico datado en la segunda mitad del siglo II d.C., con un borde de Hayes 131 como elemento más definitorio. A pesar de la ausencia de depósito funerario, creemos que podría ubicarse cronológicamente entre los siglos IV y VI d.C. si es, como parece, contemporáneo de otros restos funerarios conocidos en la ciudad, algunos de los cuales han sido excavados recientemente (Navarro 2008; Diloli et alii 2010). El cuerpo está situado alrededor de 4 metros por debajo del nivel actual de circulación de la nave de la iglesia.

\subsection{Excavación en la calle de Sant Domènech}

La segunda intervención consistió en la excavación de una cata en el exterior de la iglesia, con el objetivo de conocer la estratigrafía de este sector urbano (Fig. 3 , B), al mismo tiempo que se realizaba un seguimiento de las tareas de reurbanización de la calle. La intervención en esta tercera cata dio resultados similares a las anteriores, pues también aquí se localizaron importantes restos estructurales bajomedievales y andalusíes, si bien en este caso no dificultaron la continuación de los trabajos, que pudieron alcanzar cotas más profundas.

Bajo las estructuras y estratos medievales se localizó una segunda inhumación en fosa simple, a un metro y ochenta centímetros respecto a la cota de la calle, que pudo ser recuperado en su totalidad, con la excepción del cráneo del difunto, perdido bajo el basamento de un muro andalusí. Como en el caso anterior, la ausencia de depósito funerario hizo que la datación se efectuase por proximidad y similitud con las tumbas de las necrópolis bajo imperiales de sectores próximos, con lo que nos situaríamos en un 
horizonte de los siglos IV-VI d.C., aunque también podría ser ligeramente anterior. La fosa de la inhumación recortaba un estrato arcilloso con materiales datables hacia la segunda mitad del siglo II d.C., a pesar de la presencia de un borde de Ostia III 170, que podría situarnos en el siglo siguiente, a no ser que se tratase de una contaminación. Ya por debajo se documentaron estratos datables durante el siglo I d.C., recortados por una débil estructura de piedras unidas con barro, de forma semicircular, que seguramente formaba parte de un pozo.

Durante el seguimiento de las obras de la calle, la excavación de una zanja para la instalación de un conducto de gas, dejó al descubierto la existencia de dos estructuras murales (unidades estratigráficas 2501 y 2502) (Fig. 3A), asociadas a materiales variados, de época romana y más antiguos. El primero de estos muros fue inmediatamente documentado y cubierto con una capa de arena, ya que no impedía el curso de las obras, si bien fue imposible datarlo, puesto que solamente quedaba al descubierto su cara superior. La segunda estructura, en cambio, situada en la parte superior de la calle, a escasos metros de la cata, ofrecía visiblemente unas características especiales, al estar formada por una hilada de piedras de grandes dimensiones. La singularidad de esta construcción, que recordaba a algún tipo de fortificación, así como la antigüedad de los materiales asociados -cerámica ibérica y romana alto imperial y republicana-, motivaron su excavación en profundidad. La evolución de los trabajos aconsejó abrir un subsector a 1,10 m del tramo principal de muro para comprobar su continuidad. En este espacio salieron a la luz una serie de estructuras apoyadas a un muro central que parece ser la continuación del muro que se adosa directamente a la fortificación, que se dató en época ibérica.

\section{LA SECUENCIA OCUPACIONAL}

Finalizada la intervención y analizados los materiales y estructuras documentadas, se pudieron distinguir al menos cuatro momentos de ocupación de este espacio urbano, desde época preibérica hasta la Antigüedad Tardía.

\subsection{El HORIZONTE PREIBÉRICO}

Los estratos inferiores documentados en la calle de Sant Domènech no han proporcionado restos estructurales, pero se registró la presencia de cerámica

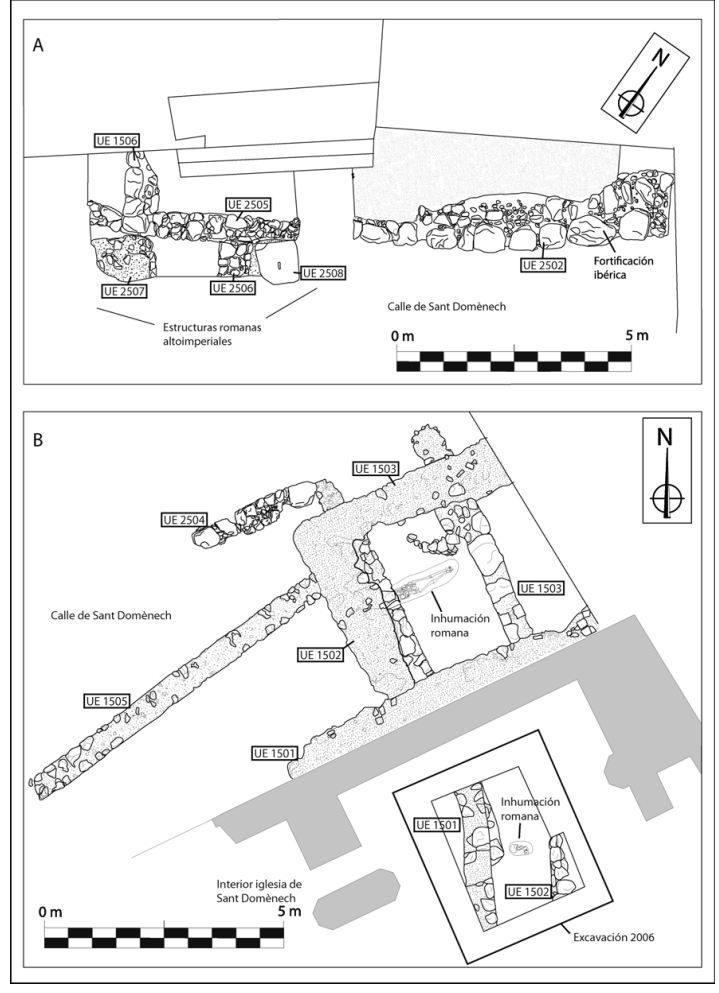

Figura 3. Plano general de la excavación con indicación de las principales unidades estratigráficas.

elaborada a mano, en buena parte bruñida, acompañada de restos de ánfora fenicia. En realidad se trata de un conjunto pequeño -las piezas están muy fragmentadas y rodadas-, pero coherente, que marca un horizonte de la Primera Edad del Hierro, grosso modo del siglo VII a.C. Se trata de elementos claramente situados en posición secundaria, depositados en la parte baja de la ladera del monte, justo en la calle Sant Domènech, probablemente a causa de factores naturales tales como la erosión de la cima del tozal, en donde tenemos que postular para estos momentos la existencia de un asentamiento. No podemos descartar totalmente la posibilidad de que en el momento de construcción del muro ibérico posterior se modelase en cierta medida la ladera, retirando tierra de unos sectores para depositarla en otros, de modo que la formación de este estrato pudiera ser de origen antrópico, aunque creemos que se trata más bien del resultado de procesos de deyección naturales. En realidad ya se tenía constancia de una ocupación humana preibérica de esta zona, tal y como se comprobó durante el estudio de los materiales depositados en el antiguo Museo Municipal de Tortosa, donde apareció una pequeña cantidad de fragmentos de cerámica similar (Diloli y Ferré 2008b). 


\section{2. ÉPOCA IBÉRICA}

El elemento más destacable del conjunto exhumado durante las excavaciones llevadas a cabo en la calle Sant Domènech es un muro (U.E. 2502) que presenta 5,40 metros de longitud visible. Su anchura es de 1,5 metros, y su sección muestra que la mitad corresponde, con entradas y salientes, a una hilada de grandes bloques de piedra no escuadrada que forman la cara vista del muro, tras la que se acumula una gran cantidad de piedra pequeña y mediana, a modo de relleno. El tamaño medio de las piedras que forman la base de la estructura oscila entre 0,60 y 1,20 m de longitud y 0,50 y $1 \mathrm{~m}$ de alto. La cara interna del muro no posee la fortaleza de la externa, por lo que suponemos que su función sería a la vez de muro de aterrazamiento y de base de una estructura defensiva avanzada. Para conferir mayor solidez y unidad al muro no se utiliza ningún mortero, solo barro y ripio para encajar entre sí las piedras. De este paramento se conservan dos hiladas, con una altura de poco más de un metro. El extremo sur de la construcción consta de una única hilada a lo largo de un metro, formada por un solo bloque de piedra, a partir del cual parte un segundo muro (U.E. 2505) que sigue prácticamente la misma dirección que el anterior. En este caso, se trata de una construcción más modesta de cerca de 60 centímetros de anchura, elaborado a base de piedras de variadas dimensiones unidas con barro. Este segundo muro se pierde por su extremo sur, más allá del límite de excavación, siguiendo aproximadamente el mismo trazado que la actual calle de Sant Domènech. En una

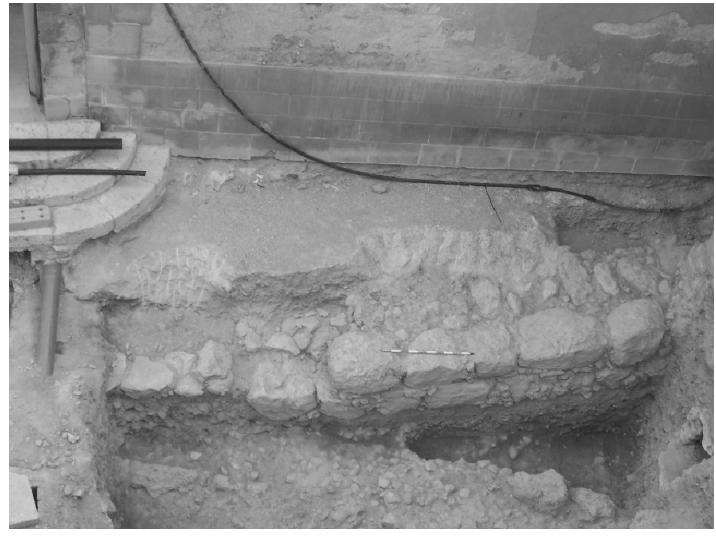

Figura 4. Fotografía de la fortificación ibérica.

publicación previa interpretábamos los muros 2502 y 2505 como una única estructura cuyos límites se perdían por ambos extremos del área de excavación (Diloli y Ferré 2008b). Con todo, después de una revisión exhaustiva del registro estratigráfico y material, no hay duda de que se trata en realidad de dos muros distintos, uno apoyado sobre el otro. Hay que indicar que el muro 2502 no se sustenta sobre la roca natural, sino sobre un estrato de arcilla rico, como ya hemos indicado, en materiales preibéricos (U.E. 2015). A pesar de ello, el suelo natural de conglomerado está muy próximo, puesto que aparece a menos de un metro de la superficie frontal del muro, en forma de una cresta que se aproxima progresivamente a éste hasta que la trayectoria de los dos se cruza. A partir de esta cresta se extiende en leve progresión descendente una superficie irregular de suelo rocoso.

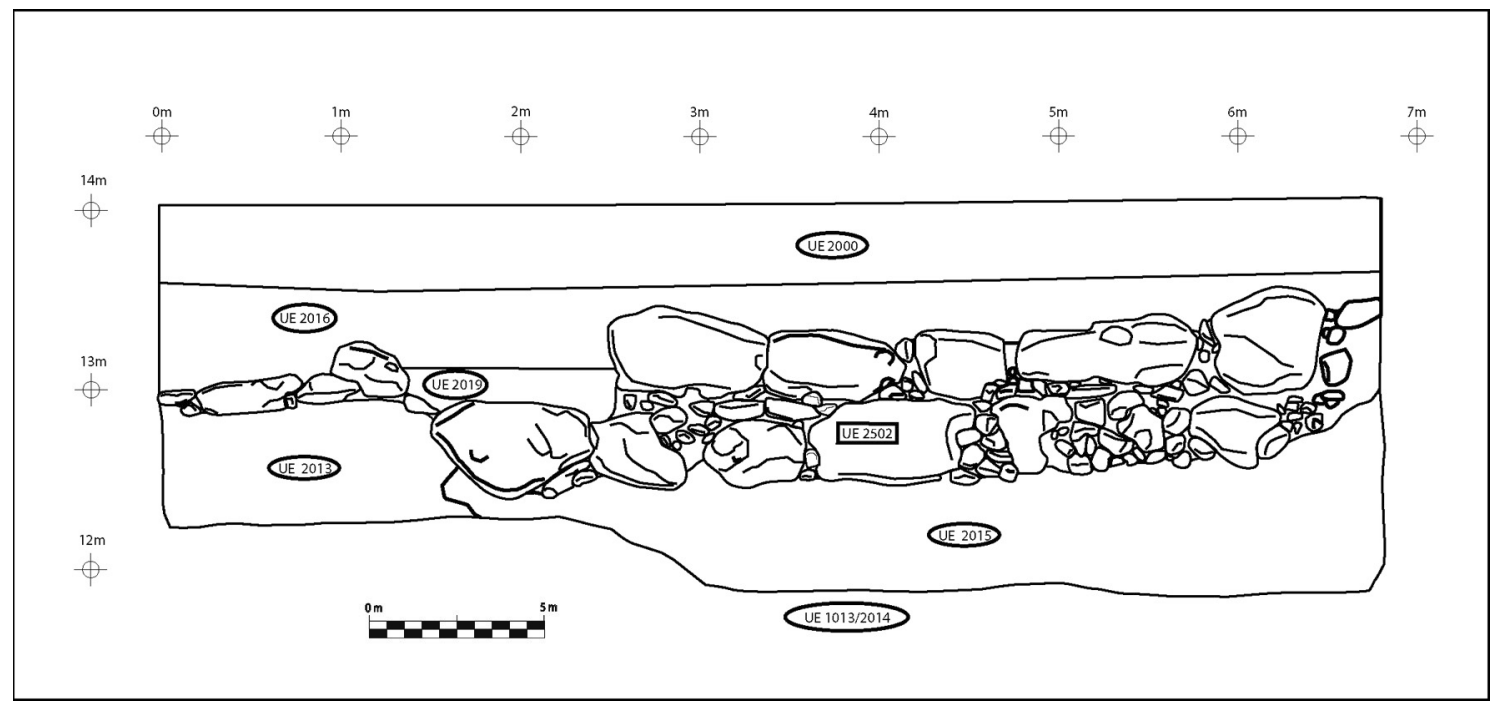

Figura 5. Planta de la estructura de época ibérica localizada en la calle Sant Domènech, con indicación de las principales unidades estratigráficas. 
El muro 2502 se encontraba cubierto por un nivel arqueológico (U.E. 2016) en el que había materiales cerámicos de época ibérica y romana que no iban más allá del siglo I de nuestra era. Delante de la cara frontal del muro se localizaron dos estratos (U.E. 2007 y 2008), cuya formación hay que situar en momentos intermedios entre la construcción y la destrucción del mismo. Estos niveles se sobreponen a un estrato que contiene únicamente materiales de la primera edad del hierro (U.E.2015). En el caso de la UE 2007, que sería el nivel más moderno, la presencia de fragmentos anfóricos itálicos, concretamente un borde de Dressel IA, y el pivote de una Lamb. 2. sitúan su cronología en torno al siglo I a.C. Por su parte, la U.E. 2008 no cuenta con indicadores tan fiables: hay presencia de fragmentos de Campaniense A, la mayoría informes, pero también un borde de Lamb. 27, datable en el paso del siglo III al II a.C. En conjunto, se trata de un nivel que por los materiales que contiene, se formaría a partir del siglo II a.C. Estos estratos no se extienden regularmente sobre la plataforma rocosa, sino que aparecen adosados a la cara frontal del muro, de modo que es probable que se trate de acumulaciones de sedimento precipitado desde su parte superior, tal vez en un momento en que la función original de la estructura había perdido parte de su sentido. El resto de la plataforma rocosa parece ser que estuvo al descubierto, al menos hasta finales del siglo II d.C., momento en que se formaría el estrato 2009. A pesar que no hay elementos relacionados directamente con la construcción del muro 2502, se observa como ya hemos indicado, que este se cimenta directamente sobre un nivel preibérico (2015), que está cubierto a la vez por un estrato del siglo II a.C. (2008), que también se adosa al extremo inferior del muro defensivo (2502).

Con estos datos nos atrevemos sugerir un momento de construcción del paramento en época ibérica, siendo

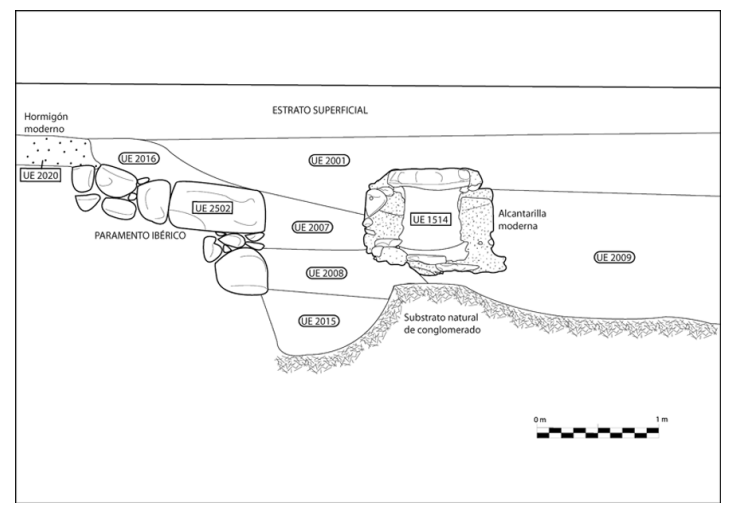

Figura 6. Sección de la estructura de época ibérica localizada en la calle Sant Domènech, con indicación de las principales unidades estratigráficas. en este caso la documentación histórico-arqueológica la que nos puede ayudar a precisar con más exactitud su edificación. Creemos que es coherente emplazar su construcción a finales del siglo III a.C., relacionándola con el transcurso de la Segunda Guerra Púnica, en un momento en que sabemos con certeza que las tierras del Ebro estuvieron muy implicadas en el conflicto, tal como relata Tito Livio, con acontecimientos como el ataque romano sobre Hibera o el establecimiento de un campamento en la desembocadura del río (Liv. XXIII, 28, 9-12; XXV, 37, 6-7; XXVI, 17, 2-3; XXVI, 41, 1-2; XXVIII, 42, 3-4) (Noguera 2008; 2011).

En este sentido, las razones por las que proponemos esta datación se resumen en dos puntos fundamentales:

- La propia contienda constituye un estado de gran inseguridad sobre unas comunidades humanas no acostumbradas a hechos bélicos de magnitud similar a la Segunda Guerra Púnica. La construcción de nuevas fortificaciones y el reforzamiento de las ya existentes es una respuesta lógica a esa inseguridad, y pueden encontrarse muestras de tal comportamiento en varios núcleos ibéricos de la región; cinco km río arriba de Tortosa, en el poblado de Les Planetes (Tortosa, Baix Ebre), se modificaron los accesos al interior del asentamiento, con la inutilización de su única puerta conocida, situada junto a la torre que corona el poblado (Diloli et alii 2009). Más al norte, en el asentamiento de L'Assut de Tivenys se documentan varias reformas y mejoras en su ya de por sí aparatoso sistema defensivo, e incluso la destrucción violenta de la llamada torre T-3 en los últimos tiempos de la contienda, o en el inicio de la dominación romana (Diloli 2009). En el Castellet de Banyoles de Tivissa es muy posiblemente en estos momentos cuando se construyeron sus dos impresionantes torres de planta pentagonal flanqueando el acceso al poblado (Pallarés 1983-84), a pesar de las dificultades que entraña la datación en nuestros días de unos restos excavados de antiguo, a lo que se añade el hecho de que las torres fueron objeto de una restauración en los años cuarenta, tal como han puesto de manifiesto las recientes campañas de excavación (Asensio et alii 2011). A estos problemas hay que sumar la alternativa propuesta por Pierre Moret en una publicación reciente, en la que defiende una cronología de la segunda mitad del siglo II a.C., con el asentamiento ya bajo control romano (Moret 2008). Continuando hacia el interior, en el poblado del Coll del Moro de Gandesa, se producen unas reformas destinadas a aumentar la capacidad defensiva del asentamiento, con el levantamiento de un sistema amurallado con tres bastiones semicirculares, que en uno de los casos se aprovecha para llevar a cabo actividades de tipo económico (Blasco y Rafel 
1995); en el Bajo Aragón, en este mismo momento se fecha la construcción de la gran torre semicircular que protege el acceso principal de San Antonio de Calaceite, complementada por un foso y formando un estrecho corredor de fácil defensa (Moret 1996: 424-5; Moret et alii 2007: 157).

- Durante la segunda mitad del siglo III a.C. se materializan arquitectónica y urbanísticamente importantes cambios en la sociedad ibérica de la Cataluña meridional y áreas adyacentes. La configuración del Castellet de Banyoles como un gran oppidum con grandes y complejas unidades residenciales, edificios públicos o cultuales y fortificaciones sofisticadas, se da en estos momentos. Poco más o menos en el mismo período aparece un gran edificio residencial en Alorda Park (Calafell), se construye el barrio bajo de San Antonio de Calaceite, y aparecen varias unidades residenciales de grandes dimensiones en la Cella (Salou). A estas evidencias arqueológicas podemos añadir la referencia de Tito Livio acerca de Hibera, según él la ciudad más rica de la región en aquel mismo momento (Liv. XXIII, 28, 9-12). Estos cambios suponen importantes reformas en la estructura interna de los núcleos en los que se llevan a cabo, lo que puede conllevar sensibles ampliaciones de sus respectivos recintos urbanos y, por lo tanto, la construcción de nuevas fortificaciones.

Volviendo al muro tortosino, ya hemos comentado que se trata de una estructura de aterrazamiento que salva un desnivel importante entre dos plataformas. Ahora bien, dada su anchura, técnica constructiva y situación topográfica, creemos que solo puede tratarse de un aterrazamiento defensivo, es decir, su función original es la de fortificación. En efecto, un simple muro de aterrazamiento no requiere una anchura de $1,5 \mathrm{~m}$, como se pone de relieve al observar estructuras cercanas con esa misma función, como el muro 2505, que se le adosa, y con una anchura que no llega a la mitad del primero. Por otro lado, el aparejo que conforma el muro 2502, fabricado a partir de grandes bloques de piedra sin escuadrar, es una muestra de monumentalidad que creemos compatible solamente con un tipo de construcción pública, como es el caso de las murallas o muros defensivos de un asentamiento importante. Algunos de sus bloques miden más de un metro de lado, que son las dimensiones a partir de las que algunos investigadores creen conveniente hablar de aparejo megalítico en la arquitectura defensiva ibérica (Moret 1996: 86). Además, la dirección del muro sigue un trayecto que recorrería, por lo menos parcialmente, la falda del tozal de la Zuda, en cuya parte superior hemos de situar un núcleo ibérico (Diloli 1996, 1997), que tendría que haber estado dotado de importantes defensas (Diloli y Ferré 2008b). Esta fortificación toma la forma de un gran muro posiblemente coronado de amplias terrazas desde las que se podría gestionar la defensa con facilidad de movimientos, dispuesta en relación al relieve rocoso del lugar, que haría del cauce del barranco del Rastre una suerte de foso natural. El uso de bloques de piedra de grandes dimensiones puede ser atribuido a la voluntad de ofrecer una imagen de fuerza e invulnerabilidad respecto a un potencial agresor externo, y contrasta con las más modestas dimensiones de los aparejos utilizados normalmente en las fortificaciones ibéricas de la región, con la excepción quizás del Castellot de la Roca Roja (Benifallet, Baix Ebre) (Belarte et alii 2002).

Esta fortificación fue parcialmente derruida seguramente ya en la primera mitad del siglo I d.C., teniendo en consideración el contenido cerámico del estrato de arcilla fina que la cubre. Se trata más bien de un desmontaje selectivo, ya que no es total, y los restos que no se derriban son aprovechados como un muro de aterrazamiento de escasa altura, ahora ya sin funciones defensivas, al que se añaden nuevas paredes con esa misma finalidad, como es el muro 2505. Esta configuración perdura hasta finales del siglo II d.C.

Una de las cuestiones que se han planteado es si el trazado de la muralla realmente acababa en el punto que se hizo visible durante la excavación, o si seguiría más allá, rodeando la colina. En este sentido, el marcado carácter irregular de la ladera seguramente haría complicado, aunque no imposible, un trazado continuo de una línea mural en dirección sur con de la envergadura de la que estamos tratando, por lo menos sin grandes obras de preparación del entorno, lo que hace concebible la existencia de un trazado discontinuo, condicionado en buena parte por el relieve.

\subsubsection{El papel del relieve}

Hay que tener en cuenta como mínimo dos características básicas del entorno físico de la zona para entender la evolución urbanística, no solo de la calle de Sant Doménech, sino también de toda la ladera meridional de la Zuda a lo largo de los siglos:

En primer lugar, la ocupación urbana de la zona implica grandes obras de aterrazamiento. En este sentido, hemos documentado un acondicionamiento por lo menos desde época ibérica, pero también aterrazamientos de época alto imperial, bajo imperial, andalusí, y posteriores, tal y como se ha observado en las recientes excavaciones llevadas a cabo en las calles de Sant Domènech, Sant Felip Neri y la Mercè.

En segundo lugar, debemos destacar la irregularidad del suelo natural rocoso. Este, formado por con- 
glomerados cuaternarios, aparece en forma de grandes bloques diferenciales, lo que da lugar a bruscos desniveles, suavizados por la acumulación de capas de arcillas y grava, de origen tanto natural como antrópico.

A la vista de los recientes trabajos arqueológicos realizados en la zona, parece ser que la línea que une la calle de Sant Domènech con la de la Mercè es donde se sitúa el último gran conjunto de bloques de conglomerado que sobresale de la línea de suelo natural de ladera del monte, antes de precipitarse al fondo del cauce del barranco. Este estribo causa un desnivel de varios metros que, en algunos puntos, cae en vertical. Con todo, no es un bloque compacto, sino muy irregular, y es evidente que las tareas de aterrazamiento y urbanización de la zona, al menos desde época romana, tuvieron que comportar un profundo cambio en la fisonomía del lugar.

El importante desnivel existente entre la cúspide del bloque de conglomerado y el resto del suelo natural de la ladera podría haber jugado un papel importante en el planteamiento de la construcción de la fortificación ibérica, puesto que esta se sitúa en una posición elevada respecto a la ladera, e inaccesible desde cotas inferiores, cercanas al lecho del barranco, que habría actuado como un foso natural acentuando el carácter defensivo de este punto.

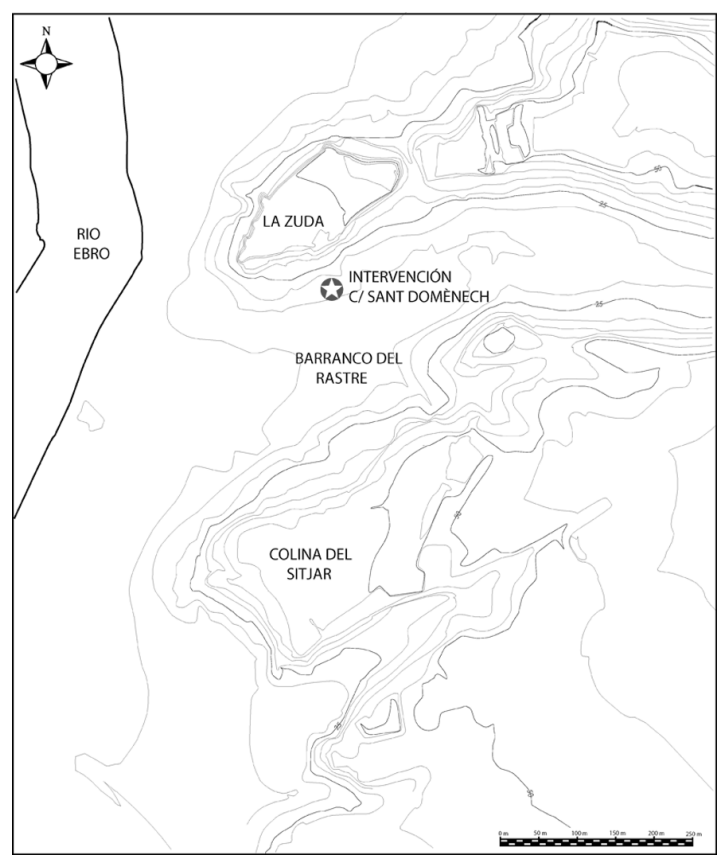

Figura 7. Relieve de la ciudad de Tortosa, en relación con el río Ebro y el Barranco del Rastre.

\subsubsection{Una fortificación ibérica}

La forma adoptada por la fortificación tortosina, la de un aterrazamiento defensivo, es una solución conocida en muchos otros asentamientos ibéricos situados en ladera, como es el caso, entre otros, de Torrelló d'Onda (Castelló, 400-200 a.C.), la Serreta d'Alcoi (Alicante, 425/400-300 a.C.), Cova Foradà (Liria, Valencia, Iberico pleno-alto Imperio), Castell Barri (Gerona, siglo V a.C.), posiblemente el Castell de la Fosca (Palamós, Gerona, siglo IV a.n.E.) (Moret 1996).

También debemos destacar cierta similitud con determinadas estructuras que en algunos asentamientos están íntimamente asociadas a la presencia de fosos, como es el caso de los poblados aragoneses de San Antonio de Calaceite, Valdetaus de Tauste, la Tallada de Caspe, o Castellans de Cretas. En estos yacimientos se da la existencia de muros situados en ladera, realizando funciones de aterrazamiento a la vez que protegen los puntos más accesibles de los fosos para impedir que estos puedan ser fácilmente superados por hipotéticos asaltantes (Romeo 2002). En el caso de Castellans de Cretas, estas estructuras también han sido interpretadas como refuerzos o muros de contención, aunque sin función defensiva (Melguizo y Moret 2007). En Puig de la Nau (Benicarló) se han considerado como antemurales una serie de estructuras situadas delante de la cortina principal, a modo de barbacana o incluso de epikampion (Oliver y Gusi 1995; Dies 2006; Oliver 2006), aunque al menos uno de ellos podría actuar como terraplén (Moret 1996: 446, Dies 2006). En Castellet de Bernabé, (Llíria, Valencia), hay una serie de muros de contención en la ladera de la elevación donde se encuentra el asentamiento, para el mantenimiento de una rampa de acceso (Guérin 2003: 4-6, 224, 225).

En el caso tortosino, el sentido pleno de las estructuras localizadas no está tan claro. Al no disponer de una visión de conjunto, no podemos establecer el valor exacto que el muro tendría en relación al sistema defensivo al que pertenece, pero si tenemos en cuenta su proximidad a un brusco desnivel del terreno natural, posiblemente acentuado o manipulado antrópicamente, podría tratarse de un elemento destinado a la protección de la parte más baja de la colina de la Zuda, a la vez que un aterrazamiento. Es en este caso la cronología que proponemos para su construcción la que nos dirige hacia su funcionalidad, pues el paramento se erige en un momento en que se constatan cambios bruscos en la organización del territorio ibérico del bajo Ebro, asociados a la formación de auténticas ciudades destinadas a dirigir esta región (Castellet de Banyoles en la Fòia de Mora y la 
Hibera citada por Livio en el tramo inferior del Ebro), en un proceso de formación estatal solo truncado por la conquista romana.

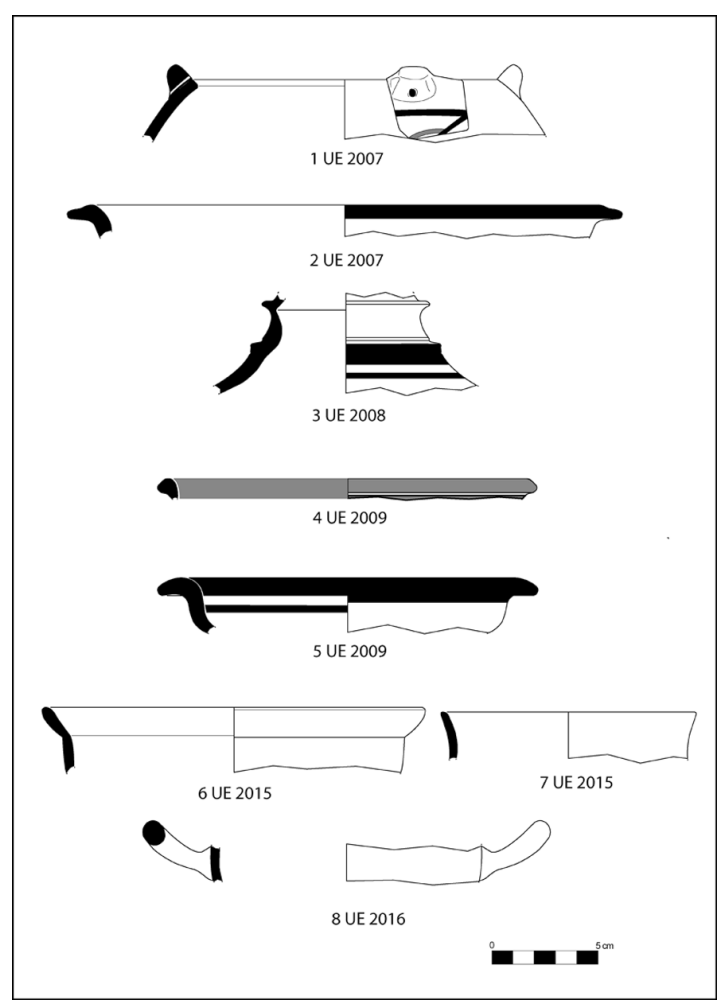

Figura 8. Materiales protohistóricos localizados en la calle Sant Domènech: 1. urna ibérica de cierre hermético con orejetas; 2. tinaja ibérica; 3. pithiskoi; 4. vaso de barniz negro ático de la forma Lamboglia 22 / Morel 2681 a; 5. plato ibérico; 6 y 7. cerámica a mano preibérica; 8.- imitación ibérica de skyphos.

\subsection{LAS REFORMAS ALTO IMPERIALES}

El derribo parcial de la fortificación ibérica, producido durante la primera mitad del siglo I d.C., supondrá un cambio en la función del antiguo elemento defensivo. Una alteración que hay que relacionar a nivel político y social con la pujanza de Dertosa como ente constituido jurídicamente, tal y como muestran la emisiones monetarias locales de época tiberiana, en las que aparece la leyenda Dertosa Municipium Hibera Iulia Ilercavonia (Diloli 1996; Llorens y Aquiluè 2001) y también a nivel administrativo con la aparición de los primeros magistrados en la ciudad a partir del siglo I d.C. ${ }^{1}$.

\footnotetext{
${ }^{1}$ Inscripciones de Marcus Porcius Terentinus, duumviro (CIL II $\left.{ }^{2} / 14,794\right)$ y de Marcus Porcius Theopompus, seviro
}

Hemos usado la palabra derribo para definir la última fase de la fortificación ibérica, aunque en realidad deberíamos hablar más bien de desmontaje selectivo, ya que no supone su eliminación total. Los restos se amortizan como muro de aterrazamiento de poca altura, sin ningún tipo de función defensiva, al que se adosan una serie de muros posteriores. El primero de ellos, el muro 2505, está alineado con el muro ibérico y lo sustituye parcialmente en las funciones de terraza constructiva. No obstante, su origen no está completamente aclarado, puesto que recorta estratos tardorepublicanos, con una mayoría de material ibérico, mientras que puede situarse su ruina a partir del siglo II d.C., cuando se le adosa el muro 1506. Pensamos que su construcción podría situarse durante el siglo I d.C., coincidiendo con la destrucción parcial de la muralla ibérica. La secuencia estratigráfica del muro 2505 ha permitido recuperar indicadores cronológicos que en ningún caso superan la etapa antonina. El lote está formado por importaciones anfóricas de origen itálico, concretamente un pivote de Dressel 1 y otro de Lamb. 2, sudhispánico, con la forma Lomba do Canho 67 (LC.67) y elementos de origen bético. La vajilla fina presenta un único ejemplar de terra sigillata itálica, constituido por la forma Consp. 26/27 con sello (tipo 109 CVAr) (Oxé y Comfort 1968), mientras que el volumen total de formas corresponde a elementos de tipo sudgálico, como las Drag. 15/17 y Ritt. 8, y sobre todo, hispánico. En último término las importaciones de cerámica de cocina africana se ven limitadas a la forma Ostia II 302, que se desarrolla durante el período julio claudio, y a la cazuela baja Lamb. 9A, de época flavia. Vale la pena destacar el hallazgo de una fíbula Alesia Preaucissa, tipo 19.1.b b (Erice Lacabe 1995), datable a mediados del siglo I a.C.

La información expuesta, a pesar de ser parcial debido a las limitaciones inherentes a una excavación de tipo urbano, hace que se pueda hablar de obras de nivelación o aterrazamiento de época alto imperial, seguramente augústeas, en este sector de la ciudad, un hecho hasta ahora no documentado en anteriores intervenciones arqueológicas.

Al muro 2505, realizado a base de mampostería irregular, se le adosan dos nuevas estructuras que constan de una única hilada de piedras, los muros 2506 y 2507. Ambos se sitúan en perpendicular al muro de aterrazamiento y cuentan con una capa de mortero de cal que los cubre. Sobre 2507 se da la existencia de un sillar de forma cúbica, con encaje de sujeción, siendo este un elemento que se repetiría en la estructura 2506, en donde solo queda su impresión en el mortero.

$\left.\overline{\text { augustal (CIL II }}{ }^{2} / 14,795\right)$ (Mayer y Rodà 1985; Rodà 1989). 
Sobre 2505 se extiende un nivel de derrumbe (2002), sobre el que se sitúa otro muro en sentido perpendicular, el muro 1506, levantado sobre las ruinas del anterior, al que se adosa el estrato 2004. Esta última estructura se pierde bajo el patio del edificio renacentista del colegio de Sant Domènech y Sant Jordi, y le suponemos provisionalmente una cronología del siglo II d.C. sin descartar que pueda ser posterior.

En vista de los datos presentados, no estamos en condiciones de interpretar la función de las estructuras de cronología romana alto imperial, debido tanto a las limitaciones de la intervención, como al estado de conservación de los restos. Es presumible que se utilizase la vieja fortificación ibérica como cantera, mientras que la presencia de un sillar escuadrado podría estar indicando la existencia de una edificación con un cierto grado de monumentalidad. En todo caso, forman parte del mismo horizonte cronológico de algunos de los restos que están siendo excavados en las calles vecinas de Sant Felip Neri y la Mercè, las cuales podrán aportar en breve un conjunto de datos más rico que las presentes para el conocimiento del período alto imperial de esta zona de la ciudad.

El conjunto de estructuras alto imperiales halladas en la calle de Sant Domènech se derriba hacia finales del siglo II d.C., y sus restos son cubiertos por una importante capa de tierra, escombros y restos de material constructivo que se distribuye por toda la ladera de la Zuda hasta el cauce del barranco del Rastro. Este estrato de abandono se sitúa cronológicamente hacia finales del siglo II d.C., documentándose producciones en terra sigillata africana del tipo A como material más moderno, concretamente las formas Lamb. 1A y Lamb. 2A, junto con vajilla de cocina africana, cazuelas del tipo Lamb. 9A y Lamb. 10A/Hayes 23B, concordando plenamente con los estratos recortados por las fosas de las tumbas halladas tanto en el interior como en el exterior de la iglesia de Sant Domènech. El mismo estrato de abandono se ha detectado ya en otras excavaciones, como en las ya mencionadas de Sant Felip Neri y la Mercè, pero también en la calle Montcada (Diloli et alii 2010), así como en antiguas obras urbanas en las que se documentaron restos romanos, como en la calle Mercaders, la plaza dels Estudis, y en el edificio de la Telefónica (Navarro 2008).

Este horizonte finisecular marca, sin duda, una importante etapa de reformas urbanísticas en la ciudad romana, que incluiría el abandono y derribo de su sector más meridional, así como el arrojo de grandes cantidades de escombro desde la parte superior de la Zuda ladera abajo.

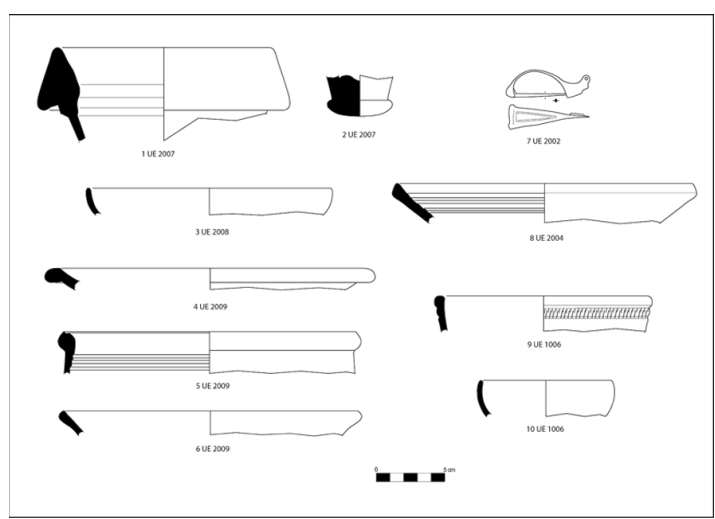

Figura 9. Materiales de época romana localizados en la calle Sant Domènech: 1. Dressel 1A; 2. Lamb. 2; 3. Lamb. 27 ; 4. Ostia III 170; 5. Ostia III 267; 6. Ostia III 332; 7. Fíbula Alesia Preaucissa, tipo 19.1.b b; 8. Ostia II 302; 9. Lamb. 2a / Hayes 9 B; 10. Ritt. 8.

\subsection{LAS SEPULTURAS BAJOIMPERIALES}

La evolución histórica del entorno de la calle de Sant Domènech en época antigua no estaría completa sin abordar la época bajoimperial. Con posterioridad a su abandono como espacio de hábitat, este sector de la ciudad es ocupado por áreas de necrópolis, más o menos dispersas, que se aglutinan en la ladera meridional de la Zuda y en el lecho del barranco del Rastre, constituyendo una de las zonas funerarias mejor conocidas actualmente en la ciudad de Dertosa. Esta área se encuentra próxima a una de las vías de acceso a la ciudad antigua, como lo confirman las abundantes noticias que existen sobre el hallazgo de inhumaciones de época romana en este sector, y que con los datos actualmente disponibles se pueden datar desde mediados del siglo IV hasta principios del siglo VI d.C. (Abril 1928; Massip 1987; Miravall 1986; Navarro 2008).

En anteriores trabajos (Navarro 2008) interpretábamos la aparición de estructuras altoimperiales en el sector de Sant Domènech como una posible monumentalización del anterior sector fortificado, aprovechando la antigua línea de defensa ibérica. Se consideraba esta hipótesis en función de las áreas de necrópolis de época romana localizadas en este sector, proponiendo una primera línea de cierre del recinto amurallado romano. Los datos se basaban en la existencia de un potente muro de piedra, siguiendo una disposición este-oeste y datado entre los siglos III y IV d.C., que fue localizado en el Aula Mayor de la catedral de Tortosa (Arbeloa 2008). La distribución funeraria del sector meridional de la ciudad favorecía, en principio, estos planteamientos, ya que esta 
se articularía en paralelo a los lienzos defensivos de época ibérica y romana, bordeando el barranco del Rastre y siguiendo una curva de nivel topográfico, a lo que hay que añadir la existencia de un antiguo camino medieval que posteriormente seguiría este mismo recorrido. A pesar de todo, la ausencia de restos de fortificación romana entre los nuevos hallazgos ha contradicho esta primera hipótesis, descartando la existencia de un lienzo defensivo romano en el sector estudiado. Lo que sí queda claro, en función de la distribución funeraria y la proximidad del cauce del barranco, es la existencia de una vía de acceso a la ciudad (Navarro 2008).

Expuestos estos planteamientos, las intervenciones realizadas en la calle de Sant Domènech y en su iglesia han permitido documentar, como hemos visto, dos inhumaciones romanas de época presumiblemente bajoimperial que situamos entre los siglos IV y VI d.C. por analogía con las excavadas en el solar de la cercana calle Montcada. Las dos sepulturas, a pesar de no estar alejadas entre sí más de tres metros en línea recta, se encontraron a una diferencia de cota de más de dos metros, por debajo de estratos andalusíes y recortando el nivel de abandono de finales del siglo II anteriormente citado. La diferencia de cota

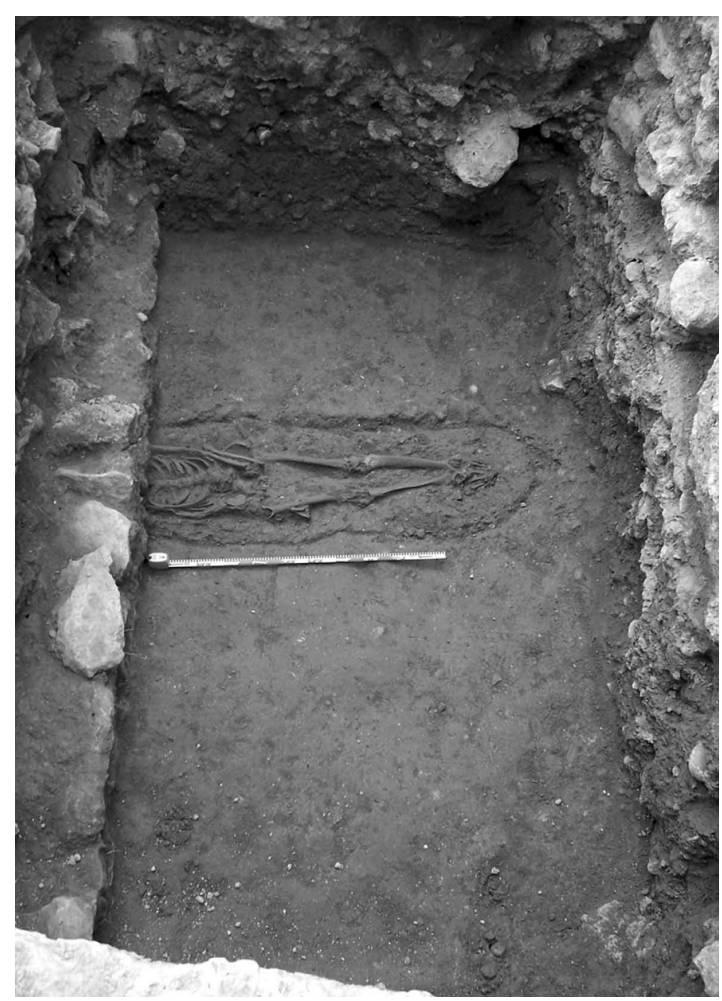

Figura 10. Detalle de uno de los enterramientos de época tardoantigua localizados en la $\mathrm{C} / \mathrm{Sant}$ Domènech. se explica por la situación en ladera de las tumbas, encontrándonos con situaciones similares en las calles de Sant Felip Neri y la Mercè.

El hallazgo de inhumaciones romanas en esta zona de la ciudad reafirma la condición de necrópolis de la misma, en un espacio extramuros, adaptándose parcialmente a los antiguos aterrazamientos, siguiendo el curso de una vía de acceso a la ciudad (Navarro 2008).

\section{CONCLUSIONES}

Con los datos que disponemos gracias a los resultados de las intervenciones que acabamos de presentar, podemos empezar a perfilar las líneas maestras de la ocupación de una amplio sector de la ciudad de Tortosa desde la Protohistoria hasta la Antigüedad Tardía.

En primer lugar es destacable la constatación de una ocupación del tozal de la Zuda durante la Primera Edad del Hierro, lo que refuerza la idea de que disponemos para esta época en el curso inferior del Ebro, y concretamente para esta región del Bajo Ebro, como una zona con una importante presencia poblacional a partir del siglo VII a.C., ocupando los altozanos más próximos al curso del río Ebro. La presencia en estos asentamientos de abundantes fragmentos de materiales fenicios procedentes del sur peninsular, en especial ánforas, nos sugiere la más que probable existencia de una red de asentamientos indígenas bien estructurada y claramente vinculada a la recepción de estas importaciones. En realidad, los textos clásicos, como se ve en Avieno, ya destacan, por lo menos desde el siglo VI a.C., la importancia del Bajo Ebro a nivel económico y humano (Avieno, Ora Marítima, 489-513).

En segundo lugar, más allá de la posibilidad de documentar la existencia de una ocupación de la ciudad en cronologías tan antiguas, también se evidencia por primera vez en Tortosa la existencia de un oppidum ibérico dotado de potentes fortificaciones. La ubicación y trazado de los restos descubiertos permiten corroborar los planteamientos de los investigadores que ya apuntaban a la presencia de este núcleo ibérico en el tozal de la Zuda (Diloli 1997, 2000, 2003; Diloli y Ferré 2008b), posiblemente sobre los restos de la anterior ocupación de la Primera Edad del Hierro. Este poblado tendría un área fortificada extensa en relación al tipo de poblamiento ibérico habitual en la región, incorporando buena parte de sus laderas oriental y meridional. Como hemos visto, la datación de estos restos puede relacionarse con la Segunda Guerra Púnica, lo que nos sitúa en un horizonte de fines del siglo III a.C. Este hecho no nos impide 
avanzar la fecha de arranque de esta ocupación ibérica hasta fechas anteriores, dada la presencia, en posición secundaria, de materiales cerámicos como por ejemplo un fragmento de labio de un vaso de barniz negro ático de la forma Lamboglia 22 / Morel 2681a, datado en el siglo IV a.C., o varios restos de urnas de orejetas, no posteriores en el curso inferior del Ebro al siglo IV a.C. o inicios del III a.C. (Belarte y Noguera 2007: 58; Diloli 2008: 246) siendo escasos los ejemplares que sobrepasan este período en el resto del área ibérica (López Bravo 2002: 101). De todos modos, desconocemos el alcance de esta ocupación al tratarse de materiales descontextualizados sin asociación a estructuras arquitectónicas.

Por otra parte, sumado a los restos estructurales y el registro cerámico de tipo ibérico disponemos de informaciones escritas de época romana que mencionan la existencia en este territorio durante el siglo III a.C. de una ciudad, Hibera, al parecer la más opulenta de la región, que fue asediada pero no tomada por las tropas romanas en su intento por retrasar la marcha de Asdrúbal hacia Italia (Liv. XXIII, 28). El texto, escrito por Tito Livio, nombra una urbe que debía de poseer importantes recursos defensivos, suficientes cuanto menos para resistir por un cierto tiempo la maquinaria de guerra romana (Diloli 2000, 2003; Diloli y Ferré 2008b). Una cita de César en la que se refiere a cómo los íberos Ilercavones que estaban en el bando pompeyano se pasaron al campo cesariano "avisados de la resolución de su ciudad, girando las banderas desde el cuerpo de guardia en el que estaban" (Caes. De bello civili, 15), o la acuñación de monedas con la leyenda Hibera Ilercavonia de finales del siglo I a.C. confirmarían la subsistencia de esta ciudad hasta cerca del cambio de era.

Las características formales de la muralla descubierta, si son representativas del conjunto de fortificaciones que protegieron el asentamiento ibérico de la Zuda, se alejan de las correspondientes a otros núcleos ibéricos conocidos del curso inferior del Ebro. En estos, ubicados en pequeños y angostos montes cerca del río, las fortificaciones por lo general solo cubren los espacios más accesibles desde el exterior, ya sea con conjuntos murales de cierta complejidad o a través de muros de cierre de dimensiones modestas, normalmente con el apoyo de torres, pero confiando en la impracticabilidad del relieve para su seguridad (Diloli y Ferré 2008a). Hay varios ejemplos de este tipo de concepción defensiva cercanos al asentamiento tortosino: Castellot de la Roca Roja (Benifallet), L'Assut (Tivenys) o Les Planetes (Tortosa), entre los mejor conocidos.

En el caso de la Zuda, parece que nos encontramos con una construcción de mayor magnitud, más aparatosa y monumental, lo que podría estar indicando una jerarquía superior del centro tortosino sobre de los asentamientos citados, un núcleo que podría identificarse perfectamente con la Hibera descrita por Tito Livio (Liv. XXIII, 28, 9-12), asumiendo un papel organizativo en este tramo inferior del Ebro en un momento de cambios substanciales en la organización ibérica, en el que destacaría la aparición de auténticas ciudades destinadas a regir políticamente el territorio².

A partir de aproximadamente inicios del siglo I d.C. se urbanizaría el sector Sant Domènech, articulándose en torno de un muro de terraza que, a su vez, se apoya sobre los restos de la antigua fortificación ibérica, desmontada ya en su mayor parte. Todo indica que se trata de un aterrazamiento general de la ladera meridional de la Zuda, aunque de momento no sepamos qué tipo de construcciones contenía, ni qué tipo de actividades albergaba. Por lo que respecta al abandono definitivo de los restos estudiados, a día de hoy podemos hablar de una reforma urbanística que supuso la eliminación generalizada de todo este barrio suburbano, si bien los condicionantes que la provocaron distan mucho de ser claros. El registro cerámico no permite atrasar esta eliminación hasta la incursión franca del año 260, que algunos autores han propuesto ante la existencia en Tortosa de potentes capas de ceniza en varios lugares del subsuelo de la ciudad (Miravall 1988), estratos de incendio por otra parte ausentes de la calle de Sant Domènech. Este horizonte cronológico de cambio de siglo es igualmente demasiado antiguo para atribuirlo a las convulsiones de la llamada crisis del siglo III. En todo caso, es interesante recordar la victoria de Septimio Severo sobre el aspirante al trono Clodio en el año 197, seguida por un período de represión contra los partidarios del segundo, numerosos entre las élites de la Tarraconense (Keay 1981: 464-466; Curchin 1991: 149-150; Costa 2009). No sabemos hasta qué punto esta represión podría tener una correspondencia material a una escala como es la aparente desaparición de un suburbio entero de la ciudad de Dertosa, pero se trata de los hechos políticos que concuerdan mejor con los restos arqueológicos, por lo menos a nivel cronológico. Asimismo no hay que olvidar la legación que el gobierno de la ciudad envió a Antonino Pío, cuya existencia se constata gracias a dos hallazgos de tipo epigráfico (Genera y Járrega 2009: 118), lo que prueba la existencia en la ciudad de alguna situación excepcional en estos momentos, aunque tampoco podemos descartar que se trate de

\footnotetext{
${ }^{2}$ Este hecho se constata también en Tivissa, con la aparición del Castellet de Banyoles a finales del siglo III a.C., una ciudad ibérica que controlaría el territorio adyacente al río Ebro entre el Pas de Barrufemes y el Pas del Ase.
} 
dinamismos de alcance puramente local, que de momento se nos escapan.

Como hipótesis, también se puede aventurar la proximidad del barranco del Rastre, caracterizado por la violencia de sus avenidas ${ }^{3}$, como uno de los elementos que pudieron afectar directamente la vida y actividad de los pobladores del lugar, si bien esta explicación no resulta del todo satisfactoria, teniendo en cuenta la situación de los restos excavados, situados en un punto relativamente elevado respecto al cauce que tendría el barranco en época romana, y por lo tanto, no expuestos de modo directo al efecto de las riadas.

Finalmente, el antiguo barrio suburbano de época alto imperial será adaptado a usos funerarios durante el Bajo Imperio.

A pesar de la obtención de datos importantes sobre varios períodos históricos, queda por resolver tanto la problemática del cierre de la ciudad romana, que como se ha visto no se realizaba por este punto de la ladera meridional de la Zuda, así como la ausencia de inhumaciones de época altoimperial en este sector de la ciudad, que únicamente aporta datos en este sentido desde mediados del siglo IV d.C. ${ }^{4}$.

\section{BIBLIOGRAFÍA}

Abril, J. 1928: Un capítol de la meva actuació a Tortosa, Tortosa.

Álvarez, R., Asensio, D., Jornet, R., Miró, M. T. y Sanmartí, J. 2008: "Residències aristocràtiques al món ibèric septentrional. El cas del Castellet de Banyoles (Tivissa, Ribera d'Ebre, Tarragona)", Seminari La cámara funeraria de Toya y la arquitectura monumental ibérica, Madrid, 87-102.

Aquiluè, X. 1995: "La cerámica común africana", Ceràmica comuna romana d'època Alto- imperial a la Península Ibèrica. Estat de la qüestió. Monografies Emporitanes VIII, Empúries, 61-74.

Arbeloa, J. V. M. 2000: "Dertosa a l'Antiguitat Tardana. Consideracions sobre els espais cultuals", Nous Col-loquis IV, 45-72.

\footnotetext{
${ }^{3}$ Tanto Abril i Guanyabéns (1931: 15-16) como posteriormente Bayerri $(1935,1960)$ (Diloli y Ferré 2008b) tratan acerca de la virulencia de las crecidas de los barrancos del Rastre y Remolins, que a finales del siglo XIX e inicios del XX provocaron en diversas ocasiones la muerte a muchos vecinos, amén de incontables destrozos.

${ }^{4}$ Hay que hacer referencia a la noticia de la existencia de una sepultura supuestamente altoimperial localizada en la cripta del templo de la Reparación, en la calle de la Mercè, a principios del siglo XX. Los datos que poseemos al respecto son poco claros, aunque destaca el hallazgo de un aureus de Nerón en la boca del difunto (Abril 1928).
}

Arbeloa, J. V. M. 2008: “Dertosa a l'Antiguitat. Aspectes d'una estructura urbana incògnita", Citerior 4, 79-96.

Asensio, D., Miró, M. y Sanmartí, J. 2003: "El nucli ibèric del Castellet de Banyoles (Tivissa, Ribera d'Ebre): un estat de la qüestió", I Jornades d'Arqueologia. Ibers a l'Ebre, recerca i interpretació. Ilercavònia 3, Tivissa, 185-203.

Asensio, D., Jornet, R., Miró, M., Sanmartí, J. 2011: "La ciutat ibèrica del Castellet de Banyoles: resultats de l'excavació del barri adjacent a les torres pentagonals (2008- 2010)", Tribuna d'Arqueologia 2009-2010, 243-263.

Baila, M. A. 1999: La ciutat de Tortosa: evolució de l'espai urbà: de la Dertosa romana a la ciutat vuitcentista, Vinaròs.

Barrasetas, E. 1993: "Plaça d'Alfons XII, Tortosa". Anuari d'intervencions arqueològiques 1982 1989. Època Romana. Antiguitat tardana, Barcelona, 62.

Bea, D., Diloli, J., Ferré, R., González, A., Kirchner, H., Vilà, J. y Virgili, A. 2012: 'L'urbanisme del suburbi meridional de la ciutat de Tortosa en època medieval (segles XI-XIV). La intervenció arqueològica efectuada al carrer Montcada de Tortosa (Baix Ebre)", IV Congrés d'Arqueologia Medieval i Moderna de Catalunya, Tarragona, 10-13 de juny de 2010, Tarragona.

Belarte, C., Noguera, J. y Sanmartí, J. 2002: “El jaciment del Castellot de la Roca Roja (Benifallet, Baix Ebre). Un patró d'hàbitat ibèric en el curs inferior de l'Ebre", I Jornades d'Arqueologia Ibers a l'Ebre. Recerca i interpretació. Ilercavònia 3, Tivissa, 89-110.

Belarte, C. y Noguera, J. 2007: La necrópolis protohistòrica de Santa Madrona (Riba-roja d'Ebre, Ribera d'Ebre), Tarragona.

Blasco, M. y Rafel, N. 1995: "El taller tèxtil del Coll del Moro de Gandesa (Terra Alta)", Tribuna d'Arqueologia 1993-94, 37-50.

Costa, J. M. 2009: "El Exercitus Hispanicus ante la encrucijada del siglo III", Gallaecia 28, 151-166.

Curchin, L. A. 1991: Roman Spain: Conquest and assimilation, London.

Curto, A., Loriente, A., Martínez, R. y Ros, E. 1986: "Resultats de les excavacions arquelògiques portades a terme l'any 1984 a Tortosa (Baix Ebre)", Tribuna d'Arqueologia 1984-1985, 115-120.

Díaz, M. y Otiña, P. 2003: "Valoración comercial de Tarraco: importacions cerámicas entre el siglo III a.C. y la dinastía julio-claudia”, Bolskan 20, 67-82.

Dies, E. 2006: "El sistema defensivo del Puig de la Nau (Benicarló). Análisis y propuesta de restitu- 
ción”, Arquitectura defensiva. La protección de la población y del territorio en época ibérica, Castelló de la Plana, 47-61.

Diloli, J. 1996: “Hibera Iulia Ilercavonia-Dertosa: l'assentament ibèric i la implantació de la ciutat romana", Butlletí Arqueològic 18, 53-68.

Diloli, J. 1997: Models d'ocupació del territori durant la protohistòria al curs inferior de l'Ebre, Tesis doctoral. Universitat Rovira i Virgili.

Diloli, J. 2000: "El curs inferior de l'Ebre durant l'època ibèrica segons les fonts clàssiques", $R e$ cerca 4, 79-104.

Diloli, J. 2003: "Cartago versus Roma. El curs inferior de l'Ebre durant la Segona Guerra Púnica", Miscelània del Centre d'Estudis de la Ribera d'Ebre 16, 213-231.

Diloli, J. 2009: "La perduración del poder en un espacio arquitectónico simbólico. La torre T- 3 del asentamiento protohistórico de L'Assut (Tivenys, Baix Ebre, Tarragona)", Trabajos de Prehistoria 66 (2), 119-142.

Diloli, J. y Ferré, R. 2008a: “Arquitectura de las fortificaciones y sus elementos defensivos en el curso inferior del Ebro durante la época ibérica", Actas del IV Congreso Internacional sobre fortificaciones. Las fortificaciones y el mar, Alcalá de Guadaíra, 291-301.

Diloli, J. y Ferré, R. 2008b: "Íberos en Tortosa. Nuevos datos sobre la protohistoria del Bajo Ebro", Saguntum 40, 109-125.

Diloli, J., Ferré, R. y Sardà, S. 2009: "Portes i accessos als recintes fortificats protohistòrics de l'àrea del curs inferior de l'Ebre", Revista d'Arqueologia de Ponent 19, 231-250.

Diloli, J., Vilà, J., González, A. y Bea, D. 2010: “Les excavacions arqueològiques al solar de l'antic I. E. S. del carrer Montcada (Tortosa, Baix Ebre)", Tribuna d'Arqueologia 2008- 2009.

Erice, R. 1995: Las fíbulas del nordeste de la Península Ibérica: Siglos I a.C. al IV d.C., Zaragoza.

Ettlinger, E., Hoffman, B., Roth-Rubi, K., Kenrick, P. M., Pucci, G., Schneider, G., von Schnurbein, S., Wells, C.M. y Zabehlick, S. 1990: Conspectus formarum terrae sigillatae italico modo confectae. Römisch-germanische Komission des deutschen archäologischen Institus zu Frankfurt A. M, Bonn.

Genera, M. 1993: "Intervencions a Dertosa (19821989)", Anuari d'intervencions arqueològiques. Època romana, antiguitat tardana. Campanyes 1982-1989, Barcelona, 53-55.

Genera, M. y Járrega, R. 2009: Aproximació a la Dertosa romana. Resultats de les investigacions arqueològiques al solar de la Costa dels Capellans, núm. 5. Tortosa (el Baix Ebre), Reus.
Genera, M. y Járrega, R. 2010: Aproximació a l'Ager Dertosanus. La vil-la romana de Barrugat, Bítem, Tortosa (El Baix Ebre), Reus.

Guérin, P. 2003: El Castellet de Bernabé y el horizonte ibérico pleno edetano. Serie de Trabajos Varios 101, Valencia.

Izquierdo, P. 1989: "Un tram de via Augusta al Perelló i una proposta de dinamització”, Butlletí Arqueològic 17, 169-191.

Járrega, R. 2007: "La problemàtica històrica i arqueològica de Dertosa: Estat actual dels coneixements i hipòtesis de treball", Butlletí Arqueològic 28, 137-197.

Keay, S. 1981: "The Conventus Tarraconensis in the Third Century A. D.: Crisis or Change?", A. King y M. Henig (eds.), The Roman West in the Third Century. Contributions from Archaeology and History, British Archeological Reports International Series 109, Oxford, 451-486.

Lamboglia, N. 1952: "Per una Classificazione Preliminare della Ceramica Campana", VV. AA (ed.), Atti del I Congresso Internazionale di Studi Liguri, Bordighera, 139-206.

López Bravo, F. 2002: "La uran ibérica de orejetas perforadas", Complutum 13, 97-116.

Massip, J. 1968: Memòria anual de l'Arxiu-Museu Municipal de Tortosa, Tortosa.

Massip, J. 1987: Un quart de segle del museu i arxiu municipal de Tortosa, Tortosa.

Llorens, M. M. y Aquilué, X. (2001): Ilercavonia-Dertosa i les seves encunyacions monetàries, Barcelona.

Mayer, M. y Rodà, I. 1985: "Consideraciones sobre el conjunto epigráfico de Dertosa", XVII Congreso de Arqueología Nacional (Logroño, 1983), Zaragoza, 701-737.

Melguizo, S. y Moret, P. 2007: "Las fortificaciones del Bajo Aragón entre los siglos III y I a. C. Un estilo regional", Paisajes fortificados de la Edad del Hierro, Madrid, 306-324.

Miravall, R. 1986: Necròpolis, sepultures i inhumacions a Tortosa, Tortosa.

Miravall, R. 1988: Tortosa, any zero, Tortosa.

Morel, J. P. 1981: Céramique campanienne: les formes (2 vol.), Roma.

Moret, P. 1996: Les fortifications ibériques, de la fin de l'âge du bronze à la conquête romaine, Madrid.

Moret, P. 2008: "À propos du Castellet de Banyoles et de Philon de Byzance: une nécessaire palinodie", Salduie 8, 193-215.

Moret, P., Benavente, J. A. y Gorgues, A. 2007: Iberos del Matarraña. Investigaciones arqueológicas en Valdeltormo, Calaceite, Cretas y La Fresneda (Teruel), Alcañiz. 
Navarro, S. 2008: Les necròpolis romanes de Dertosa (Tortosa, Baix Ebre). Estudi dels recintes funeraris i la seva interrelació amb la ciutat, Trabajo de investigación del Máster oficial en Arqueologia Clásica, URV. Inédito.

Noguera, J. 2008: "Los inicios de la conquista romana de Iberia: los campamentos de campaña del curso inferior del río Ebro", Archivo Español de Arqueología 81, 31-48.

Noguera, J. 2011: La conquista romana de Catalunya, Tarragona.

Oliver, A. 2006: El Puig de la Nau. Benicarló, Castellón de la Plana.

Oliver, A. y Gusi, F. 1995: El Puig de la Nau. Un hábitat fortificado ibérico en el ámbito mediterráneo peninsular, Onda.
Oxé, A. y Comfort, H. 1968: Corpus Vasorum Arretinorum. A Catalogue of the Signatures, Shapes and Chronology of Italian Sigillata, Bonn.

Pallarés, R. 1983-84: "El sistema defensivo frontal del Castellet de Banyoles, Tivissa, Ribera d'Ebre", Pyrenae 19-20, 113-125.

Rodà, I. 1989: "Los primeros magistrados en colonias y municipios de la Hispania Citerior (al norte de Saguntum)", J. González (ed.), Estudios sobre Urso, Colonia Iulia Genetiva, Sevilla, 345-355.

Romeo, F. 2002: "Las fortificaciones ibéricas del valle medio del Ebro y el problema de los influjos mediterráneos", P. Moret y F. Quesada (eds.), La guerra en el mundo ibérico y celtibérico (ss. VI-II a. de C.), Madrid, 153-188.

Recibido: 13-12-2011

Aceptado: 22-05-2012 